Research Article

\title{
Acoustic Performance Evaluation of Dense-Graded Asphalt Pavements in Qatar
}

\author{
Okan Sirin $\left(\mathbb{D},{ }^{1}\right.$ Md Ohiduzzaman ${ }^{(D},{ }^{2}$ Emad Kassem $\left(\mathbb{D},{ }^{3}\right.$ and Wahid Hassan ${ }^{3}{ }^{3}$ \\ ${ }^{1}$ Department of Civil \& Architectural Engineering, Qatar University, P.O. Box 2713, Doha, Qatar \\ ${ }^{2}$ Cootamundra-Gundagai Regional Council, 81 Wallendoon Street, NSW 2590, Australia \\ ${ }^{3}$ Department of Civil and Environmental Engineering, University of Idaho, Moscow, ID 83844, USA \\ Correspondence should be addressed to Okan Sirin; okansirin@qu.edu.qa
}

Received 16 January 2021; Revised 19 April 2021; Accepted 23 April 2021; Published 30 April 2021

Academic Editor: Xiaoli Liu

Copyright (C) 2021 Okan Sirin et al. This is an open access article distributed under the Creative Commons Attribution License, which permits unrestricted use, distribution, and reproduction in any medium, provided the original work is properly cited.

There is pressing and growing demand from the public to design and construct roads with a low noise level. This paper investigated the acoustic performance of asphalt pavements in the State of Qatar to assist transport authorities in designing and constructing quieter pavements. In this study, a field-testing setup was assembled to measure the tire-pavement noise of densegraded asphalt (DGA) pavements at the source using the on-board sound intensity (OBSI) method. The repeatability and reproducibility of test results demonstrated that the assembled OBSI test setup could measure the sound intensity with excellent repeatability and reproducibility. The measured noise level of existing pavements varied from 101.8 dBA to 106.2 dBA depending on the age of pavement sections. Measured noise levels of pavements in Qatar were higher than typical DGA pavements in Europe and the US. Test results also demonstrated that the acoustic performance of pavements in Qatar deteriorates faster compared to those in the US and Europe. The findings of this study demonstrate that there is a need to consider alternative asphalt mixture designs in Qatar and the Arabian Gulf. The results also showed a good correlation between the mean texture depth of studied pavement sections and noise level, especially at the low-frequency range.

\section{Background}

More people are exposed to noise pollution in modern days than any other type of pollution; hence, it possesses a significant environmental challenge for people's well-being, especially those living close to high vicinity [1]. Noise pollution due to traffic is the dominant source of environmental noise as a result of an increasing number of vehicles on the highways. Because of obvious health reasons and well-being, there is an increasing amount of public awareness and demand to mitigate traffic noise. Traditionally, noise barrier walls are generally placed along the roadway to reduce traffic noise. However, construction and maintenance of noise barrier walls are generally expensive and may not always be an effective solution since they must break the line of sight to work correctly. This is not always practically possible as gaps are required for side streets and driveways entering the highway. Sound also tends to diffract over and around barriers, thus reduces the effectiveness of the wall [2]. The presence of a hilly area provides further challenges for the effective functioning of the noise barrier wall. Therefore, there is a growing demand for highway inhibitors to reduce noise at the source [3]. Vehicles on the highway generate noise through three sources: propulsion (i.e., engine, fan, exhaust, transmission, etc.), aerodynamics, and tire-pavement interaction. Propulsion is the leading source of noise at very low speeds, while aerodynamics is the dominant noise source at very high speeds. As vehicle speed approaches around $30 \mathrm{mph}$, almost $50 \%$ of traffic noise is generated due to tire-pavement interaction [1], while the vehicle is traveling at freeway speeds, tire-pavement interaction is the dominant source (i.e., almost $80 \%$ ) of traffic noise.

Several research studies [1-4] showed that it is possible to design alternative low-noise pavement surfaces at a reasonable cost. Previous research studies also suggested that 
8-10 dBA noise reduction is possible using a modified type of asphalt mixtures depending on the existing and final pavement conditions $[3,4]$. It is essential to identify accurate and standardized pavement noise measurement systems to understand noise generation mechanisms and design quieter pavements. This is critical because data collected from the noise measurement system is usually used for two purposes: (i) evaluating the acoustics' performance of pavements over time and (ii) developing and validating the traffic noise model to predict the future acoustic performance of pavements. At present, noise measurement in the field is generally performed in two ways: (i) wayside noise measurement by placing a microphone at a certain distance and height from the centerline of the vehicle travel lane and (ii) noise measurement at the source by placing the microphone close to the pavement surface. However, if the goal is to isolate the tire-pavement noise, noise measurement at the source is more accurate than wayside noise measurement [3]. Typically, there are two techniques used for noise measurement at the source: the close proximity trailer method and the on-board sound intensity (OBSI) method. OBSI noise measurements can be collected in normal traffic conditions; therefore, a number of researchers used this method to compare the acoustic performance of various pavement types and textures [3]. Sound intensity technique is adopted in the OBSI measurement method because it is a vector quantity which rejects noise from other sources and distinguishes the propagating energy near the acoustic field and therefore can be used in the normal traffic condition [5]. In the early 1980s, General Motors introduced the OBSI measurement technique for vehicle development purposes [6]. Caltrans subsequently standardized this testing method [7].

Due to tremendous economic growth in the last decade in Qatar, its population increased rapidly, leading to an increase in the number of vehicles on the highway. Therefore, transportation authorities in Qatar invested heavily to improve the road network. Most of the pavements in Qatar are dense-graded asphalt (DGA) pavements. Macrotexture of the DGA pavement is one of the primary factors that affect tire-pavement noise. Macrotexture is associated with larger irregularities of the pavement surface and is influenced by aggregate gradation and aggregate shape characteristics. Aggregate shape characteristics include aggregate angularity and form, while aggregate gradation is mainly influenced by nominal maximum aggregate size (NMAS) and size distribution $[8,9]$. In this study, an extensive experimental noise testing program was undertaken to evaluate the acoustic performances of pavement surfaces commonly used in Qatar.

\section{Objectives and Motivation of the Study}

Qatar is a small country, and due to the limited area available, several major highways are close to residential zones; thus, there is a need to design pavements that minimize the noise level. In addition, Qatar will build almost all its modern infrastructure in the next decade to meet its 2030 vision requirements. Therefore, it is an ideal opportunity to consider noise reduction during this construction stage. Retrofitting the infrastructure system with noise barriers at a later stage will be costly and potentially ineffective. Therefore, the main objective of this study is to evaluate the noise level of existing pavements in the State of Qatar. As there is no record of tire-pavement noise measurements conducted in the Arabian Gulf to the best of the authors' knowledge, thus this work would be of interest to the regional transportation agencies. This will assist Qatar Transportation Authority to build quieter pavements as a potential alternative for traffic noise mitigation. This study also evaluated various factors such as vehicle speed, size and thread pattern of the tire, nominal maximum aggregate size, and macrotexture of the pavement surface affecting tirepavement interaction noise.

\section{Experimental Setup for Noise Testing}

In this study, tire-pavement noise was measured using the OBSI system following AASHTO standard T 360-16 [7]. Results at various pavement test sections were reported as A-weighted sound intensity level as well as $1 / 3^{\text {rd }}$ octave band frequency levels. OBSI measurements were collected using "The Acoustical and Vibrations Engineering Consultants (AVEC), Inc." system (Figure 1). Two sound intensity probes were used in this testing system (Figure 1). Each sound intensity probe consists of a pair of microphones connected with a preamplifier. Both microphones and preamplifiers were manufactured by GRAS. A microphone calibrator, model: GRAS type $42 \mathrm{AB}$, was used for calibration of the microphone. The testing rig was also supplied by AVEC Inc., which is made of aluminum and stainless steel and has a precise microphone and preamplifier mounting option according to AASHTO T 360-16 standard [7]. This testing system's major components included a 4-channel analyzer manufactured by National Instrument, AVEC OBSI software, and a semirugged laptop computer. In addition to the AVEC system, researchers also used the following equipment to conduct OBSI testing:

A sedan vehicle (model: Honda Accord, 2012) having a gross weight rating (GVWR) of 2,064 kg (4,549 lb.) was utilized for the entire testing program.

A radial standard reference test tire with a dimension of P225/60R16 97S, according to ASTM F 2493 [10], was used. In addition to the standard reference test tire, a locally available Oniza tire (P225/60R16) and a Bridgestone tire (P215/60R16) were also used for OBSI testing.

A type "A" Durometer, according to ASTM D2240-05 [11], was used to check the hardness of three tires before and after every set of noise testing.

A small weather meter was utilized to measure barometric pressure, wind speed/direction, air temperature, and humidity during the entire noise measurement testing program.

Pavement surface temperature was measured by using a Class II infrared laser gun. 


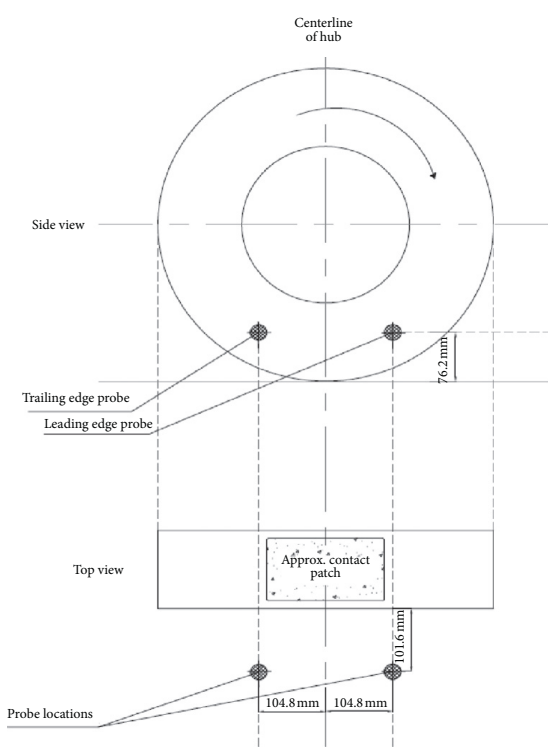

(a)

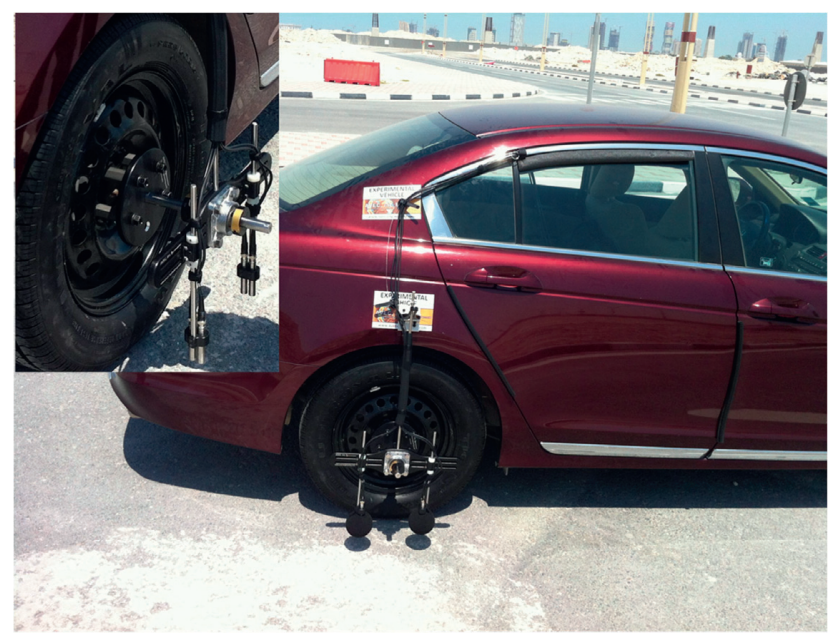

(b)

Figure 1: The OBSI testing setup. (a) Schematic diagram of probe locations. (b) Instrumented experimental vehicle.

A portable radar gun was used for speed measurement of the vehicle.

A handheld GPS was used for locating the pavement section of OBSI testing.

\section{Test Procedure and Data Quality Criteria}

OBSI tests were conducted according to AASHTO T 360-16 [7] specification. For the validity of a test run and quality control of data, the following procedures were followed.

The difference between sound intensity and pressure at any given frequency must be less than the AASHTO standard [7] specified value at each $1 / 3^{\text {rd }}$ octave band. The coherence value must be greater than 0.8 between the two microphones for the frequency range from $400 \mathrm{~Hz}$ to $4000 \mathrm{~Hz}$.

Most OBSI testing was performed at AASHTO standard [7] specified speed of $96.6 \mathrm{~km} / \mathrm{hr}(60 \mathrm{mph})$. The test run was deemed invalid by any fluctuation of specified test speed beyond a tolerable speed limit ( $\pm 1.6 \mathrm{~km} / \mathrm{hr}$ or $1 \mathrm{mph})$.

OBSI test runs for the individual pavement section were conducted in similar environmental conditions (maximum range of variability is $2 \mathrm{C}$ ).

Any test run which does not satisfy the above criteria was deemed invalid, and the test run was repeated.

\section{Location of Pavement Sections for Tire- Pavement Noise Evaluation}

OBSI noise testing was performed on three major highways and five arterial roads in Qatar. These road sections were paved with the dense-graded asphalt (DGA) surface, a typical mixture design used in Qatar. Figure 2 depicts the test

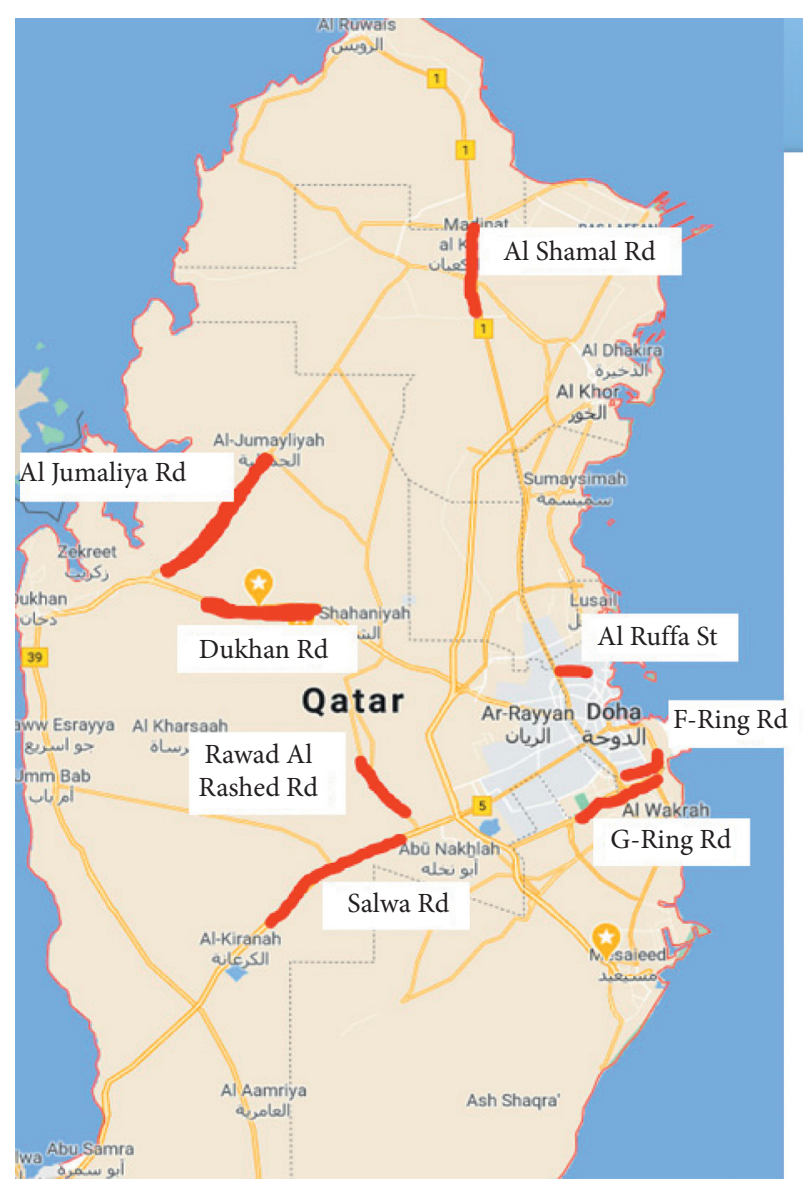

FIgURE 2: Location of OBSI test sections.

sections' location on the map. A photographic view of the selected pavement surfaces is shown in Figure 3. It is expected to have a slight variation of the noise level of the 


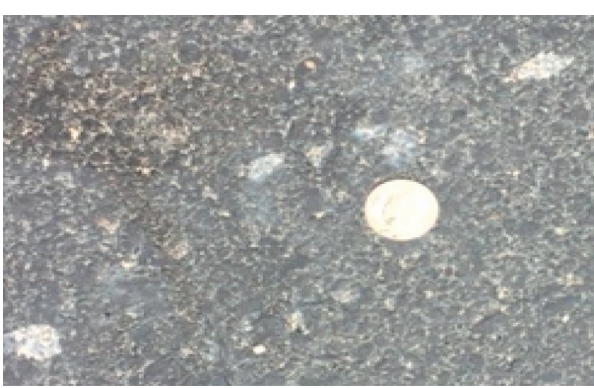

(a)

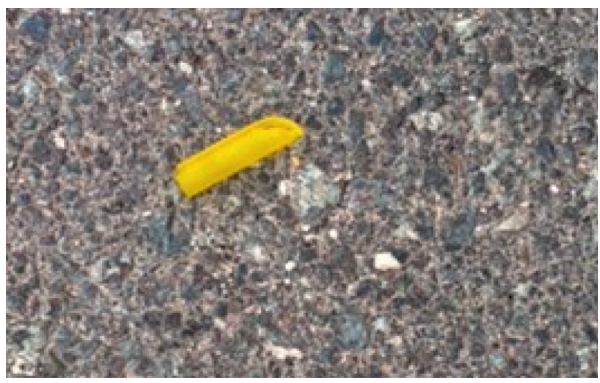

(c)

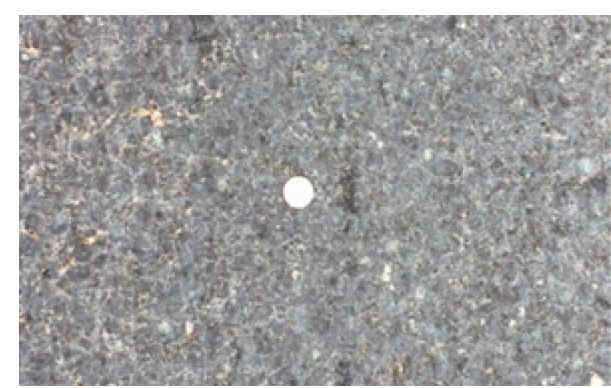

(b)

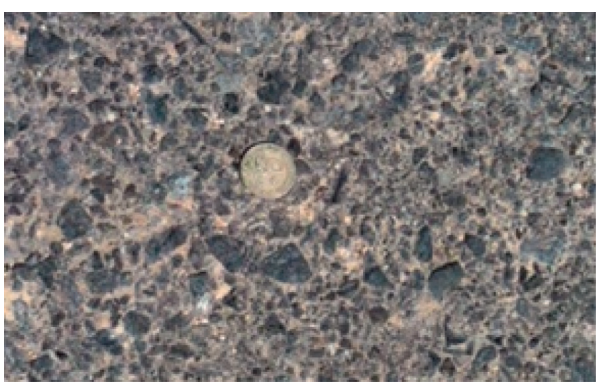

(d)

FIgURE 3: A photographic view of pavement surfaces. (a) G-Ring road (freshly paved layer). (b) Rawad Al Rashed road (1-year-old pavement). (c) Al Shamal road (6-year-old pavement). (d) Salwa road (9-year-old pavement).

asphalt pavement over distance even if the entire pavement was constructed simultaneously and operated in the same environmental conditions. The variability in the sound intensity level of various asphalt pavement sections could probably be due to slight variations in the pavement surface resulting from nonuniform compaction during construction or further densification under moving traffic with time. The presence of localized distress in the pavement section may further added to the variation in the noise level. Sandberg and Ejsmont [12] demonstrated that the variability of noise levels for different sections within individual pavement types could be from 2 to $3 \mathrm{dBA}$. Therefore, OBSI testing was performed at the multiple sections of the individual pavement. All the OBSI testing was performed at the far-right lanes of all the roads as they are the closest to the highway inhibitors and usually produce higher noise than the inside lane of the multilane highway [13]. Tests were conducted in both traffic directions to evaluate noise levels in two directions. OBSI tests were performed from March 2017 to June 2017. The as-built pavement and meteorological data during OBSI testing are presented in Table 1.

\section{Repeatability and Reproducibility of Measured Noise Data}

Repeatability and reproducibility of on-road measured noise data at the particular environmental condition and any specific type of vehicle/tire combination are important. To assess the run-to-run repeatability of noise data, the researchers selected five pavement sections in Al Shamal Road at the beginning of the noise testing program. Then, a number (five or more) of consecutive OBSI runs with the standard reference test tire were conducted on these five pavement sections to investigate the on-road run-to-run variability of measured noise data. These runs were conducted at similar environmental conditions (maximum temperature variation of $2 \mathrm{C}$ ) to avoid any influence on noise data from the changes in environmental conditions. This procedure was also repeated with other types of studied tires. The total range of overall A-weighted OBSI levels and their corresponding standard deviation for all three vehicle/test tire combinations are presented in Table 2. The observed maximum range of run-to-run variability of all vehicle/tire combinations was $0.7 \mathrm{dBA}$, with an average of $0.5 \mathrm{dBA}$. The data also indicated that the maximum standard deviation for any combination of vehicle/tire was 0.27 . The maximum range of the $\mathrm{A}$-weighted noise level and the maximum standard deviation are within the range of acceptable limits, as reported by Donavan and Lodico [14]. Therefore, the range in run-to-run variation indicates that a $1 \mathrm{dBA}$ requirement specified by AASHTO T 360-16 [7] standard is achievable by using a noise measurement testing system.

To assess reproducibility, noise testing with the standard reference test tire was conducted on selected four sections of Al Shamal Road over five days in March 2017 (March 14, 15, 19, 20, and 21). The variations between three-run datasets measured at similar environmental conditions (air temperature range of $24.5-24.9^{\circ} \mathrm{C}$ ) showed that the noise level ranges from 0.3 to $0.6 \mathrm{dBA}$ with an average of $0.45 \mathrm{dBA}$. The standard deviation of measured noise data observed for five days of testing was 0.19 . This test procedure was also repeated with other types of vehicle/tire combinations. Test results indicated that the testing system could reproduce the noise level (about a $1 \mathrm{dBA}$ variation in levels) over several days conducted within a reasonable temperature range $\left(\sim 2^{\circ} \mathrm{C}\right)$. 
TABLe 1: As-built pavement and meteorological data during OBSI testing.

\begin{tabular}{|c|c|c|c|c|c|c|c|}
\hline \multirow[b]{2}{*}{ Name of road } & \multirow[b]{2}{*}{$\begin{array}{l}\text { Pavement } \\
\text { ID }\end{array}$} & \multirow[b]{2}{*}{$\begin{array}{l}\text { Pavement age } \\
\text { (years) }\end{array}$} & \multirow[b]{2}{*}{$\begin{array}{l}\text { NMAS } \\
(\mathrm{mm})\end{array}$} & \multirow[b]{2}{*}{$\begin{array}{l}\text { Air voids } \\
\quad(\%)\end{array}$} & \multirow[b]{2}{*}{$\begin{array}{l}\text { Binder content } \\
(\%)\end{array}$} & \multicolumn{2}{|c|}{ Meteorological data } \\
\hline & & & & & & $\begin{array}{l}\text { Air temp. } \\
\quad(\mathrm{C})\end{array}$ & $\begin{array}{l}\text { Pavement temp. } \\
\text { (C) }\end{array}$ \\
\hline $\begin{array}{l}\text { Rawad Al-Rashed } \\
\text { R. }\end{array}$ & RRR & 1 & 20 & 6.2 & 3.8 & 40.1 & 54.5 \\
\hline Al Jumaliya street & JS & 1 & 19 & 6.5 & 4.1 & 38.9 & 64.8 \\
\hline G-Ring road & G-RR & New & 19 & 6.5 & 3.9 & 35.6 & 46.3 \\
\hline F-Ring road & F-RR & 2 & 20 & 7.0 & 3.9 & 36.7 & 37.2 \\
\hline Al Ruffa street* & ARS & 1 & 14 & 6.2 & 3.7 & 38.2 & 57.7 \\
\hline Al Shamal road & ASR & 6 & 14 & 6.2 & 3.7 & 24.9 & 32.2 \\
\hline Salwa road & SR & 9 & 19 & - & - & 30.2 & 47.6 \\
\hline Dukhan highway & $\mathrm{DH}$ & 7 & 14 & 6.7 & 3.7 & 35.5 & 53.4 \\
\hline
\end{tabular}

* resurfaced recently.

TABLE 2: Run-to-run variability at the start of each set of tire/vehicle combination.

\begin{tabular}{|c|c|c|c|c|c|c|}
\hline \multirow{2}{*}{ Tire } & \multicolumn{3}{|c|}{ Intensity level difference (dBA) } & \multicolumn{3}{|c|}{ Standard deviation } \\
\hline & Average range, dBA & Maximum range, dBA & Minimum range, dBA & Average & Maximum & Minimum \\
\hline SRTT & 0.5 & 0.6 & 0.4 & 0.17 & 0.23 & 0.13 \\
\hline Oniza & 0.4 & 0.6 & 0.3 & 0.21 & 0.27 & 0.12 \\
\hline Bridgestone & 0.5 & 0.7 & 0.3 & 0.16 & 0.22 & 0.11 \\
\hline
\end{tabular}

\section{Test Results and Discussion}

7.1. OBSI Level for Pavement Sections with Different Aging. OBSI noise measurements were performed on the selected pavement sections, and these sections were selected according to AASHTO T 360-16 [7] guidelines. The measured noise level was used to study the acoustic performance of DGA pavements in Qatar. Table 3 presents the average measured intensity level (MIL) of the tested sections for each pavement surface. The OBSI testing at various pavements was performed at slightly varying meteorological conditions; hence, the measured intensity level (MIL) of various pavement sections was normalized by using AASHTO T 360-16 [7] standard, as shown in the following equation:

$$
\text { IL Normalized }(\mathrm{dBA})=\mathrm{IL} \text { Measured }(\mathrm{dBA})+0.072 x\left(\text { AirTemp }^{0} \mathrm{C}-20^{0} \mathrm{C}\right)
$$

The standard deviation of sound intensity levels for different pavement surfaces is also calculated and presented in Table 3. In general, the standard deviation of the intensity level for various sections (except F-Ring Road, which is only about $5 \mathrm{~km}$ in length) increases with an increase in aging of the asphalt surface, as presented in Table 3. This probably indicates localized deterioration of asphalt surfaces such as cracking, raveling, or bleeding phenomenon with aging $[15,16]$. The OBSI measurements for the individual pavement surface type were averaged during postprocessing of data, representing the OBSI level for that pavement type. Figure 4 illustrates the average overall A-weighted OBSI level at each of the pavement in both directions of traffic. The difference between the highest and lowest measured noise intensity (average) level for the pavement surface with nominal maximum aggregate size (NMAS) of $19 \mathrm{~mm}$ is 4.1 dBA. The pavement sections tested in this study are approximately 1 to 9 years old, indicating an approximately
$0.5 \mathrm{dBA}$ per year increase of the noise level. The rate of increase of noise per year for the DGA pavement surface in Qatar is higher than the acoustic performance of other DGA surfaces in Europe and the US [2,17]. Pavements in Qatar are subjected to high temperatures (i.e., the air temperature frequently reaches or exceeds $40 \mathrm{C}$ ) during summer.

Furthermore, the number and loads of trucks are increasing on the pavement. These conditions contribute to various surface distresses (e.g., top-down fatigue cracking) that could accelerate the increase of noise in Qatar's pavements. Test results also indicated that pavements with larger NMAS of $20 \mathrm{~mm}$ (Rawad Al Rashed Road) generated higher noise than similar pavements with smaller NMAS of $19 \mathrm{~mm}$ (Jumaliya street).

The frequency data at the $1 / 3^{\text {rd }}$ octave band for each test pavement surface type is shown in Figure 5. In general, sound intensity amplitude increases with the aging of pavement. This is due to the fact that macrotexture of the 
TABLe 3: Sound intensity level for different DGA surfaces.

\begin{tabular}{|c|c|c|c|c|c|c|c|}
\hline Name of road & $\begin{array}{l}\text { Direction of } \\
\text { traffic }\end{array}$ & $\begin{array}{c}\text { No of } \\
\text { sections }\end{array}$ & $\begin{array}{c}\text { Avg. measured } \\
\text { intensity level (MIL) } \\
(\mathrm{dBA})\end{array}$ & $\begin{array}{c}\text { Standard } \\
\text { deviation (SD) }\end{array}$ & $\begin{array}{l}\text { Max. MIL } \\
\quad(\mathrm{dBA})\end{array}$ & $\begin{array}{l}\text { Min. MIL } \\
\quad(\mathrm{dBA})\end{array}$ & $\begin{array}{c}\text { Avg. normalized } \\
\text { intensity level }(\mathrm{dBA})\end{array}$ \\
\hline \multirow{2}{*}{$\begin{array}{l}\text { Al Ruffa St } \\
\text { (ARS) }\end{array}$} & $\begin{array}{l}\text { Westbound } \\
\text { (W) }\end{array}$ & 4 & 100.9 & 0.31 & 101.4 & 100.7 & 101.8 \\
\hline & Eastbound (E) & 4 & 101.5 & 0.19 & 101.7 & 101.2 & 102.3 \\
\hline \multirow{2}{*}{$\begin{array}{l}\text { Al Jumaliya St } \\
\text { (JS) }\end{array}$} & $\begin{array}{l}\text { Northbound } \\
(\mathrm{N})\end{array}$ & 4 & 101.3 & 0.15 & 101.5 & 101.1 & 102.6 \\
\hline & $\begin{array}{l}\text { Southbound } \\
(\mathrm{S})\end{array}$ & 4 & 100.7 & 0.15 & 100.9 & 100.5 & 102.1 \\
\hline \multirow{2}{*}{$\begin{array}{l}\text { G-Ring Rd (G- } \\
\text { RR) }\end{array}$} & $\begin{array}{l}\text { Westbound } \\
\text { (W) }\end{array}$ & 5 & 101.2 & 0.2 & 101.4 & 100.9 & 102.4 \\
\hline & Eastbound (E) & 5 & 101.5 & 0.12 & 101.7 & 101.4 & 102.6 \\
\hline \multirow{2}{*}{$\begin{array}{l}\text { Rawad Al } \\
\text { Rashed Rd } \\
\text { (RRR) }\end{array}$} & $\begin{array}{l}\text { Northbound } \\
(\mathrm{N})\end{array}$ & 5 & 102.4 & 0.2 & 102.7 & 102.1 & 103.9 \\
\hline & $\begin{array}{l}\text { Southbound } \\
(\mathrm{S})\end{array}$ & 4 & 101.9 & 0.2 & 102.1 & 101.6 & 103.4 \\
\hline \multirow{2}{*}{$\begin{array}{l}\text { Dukhan Hwy } \\
\text { (DH) }\end{array}$} & $\begin{array}{l}\text { Westbound } \\
\text { (W) }\end{array}$ & 9 & 101.9 & 0.3 & 102.4 & 101.5 & 103.0 \\
\hline & Eastbound (E) & 16 & 101.7 & 0.3 & 102.3 & 101.4 & 102.8 \\
\hline \multirow{2}{*}{$\begin{array}{l}\text { F-Ring Rd (F- } \\
\text { RR) }\end{array}$} & $\begin{array}{l}\text { Westbound } \\
\text { (W) }\end{array}$ & 4 & 102.8 & 0.22 & 103.0 & 102.4 & 104.0 \\
\hline & Eastbound (E) & 4 & 103.0 & 0.10 & 103.1 & 102.9 & 104.2 \\
\hline \multirow{2}{*}{$\begin{array}{l}\text { Al Shamal Rd } \\
\text { (ASR) }\end{array}$} & $\begin{array}{l}\text { Northbound } \\
(\mathrm{N})\end{array}$ & 12 & 103.9 & 0.5 & 104.4 & 103.3 & 104.3 \\
\hline & $\begin{array}{l}\text { Southbound } \\
(\mathrm{S})\end{array}$ & 18 & 104.1 & 0.2 & 104.4 & 104.0 & 104.5 \\
\hline \multirow[t]{2}{*}{ Salwa Rd (SR) } & $\begin{array}{l}\text { Westbound } \\
\text { (W) }\end{array}$ & 17 & 105.6 & 0.6 & 107.1 & 105.0 & 105.9 \\
\hline & Eastbound (E) & 15 & 105.9 & 0.4 & 106.5 & 105.1 & 106.2 \\
\hline
\end{tabular}

surface changes due to pavement distress and deterioration with aging. The aging effect is more pronounced for the frequency bands less than $1000 \mathrm{~Hz}$. This is plausible as macrotexture of the surface dictates the noise generation at a low-frequency range. The highest sound intensity amplitude difference (about $7.0 \pm 0.5 \mathrm{dBA}$ ) between the highest (Salwa Road) and lowest (Al Ruffa Street) noise level of the pavement surface occurred at a frequency of $630 \mathrm{~Hz}$. The peak sound intensity amplitude for each type of test pavement was observed at the center frequency of the $1000 \mathrm{~Hz}$ band. About $4 \mathrm{dBA}$ difference in peak sound intensity amplitude was observed between the 9-year-old DGA pavement (Salwa Road) and 1-year-old DGA pavement (Al Ruffa Street). The rank order indicated by the spectra at the $1000 \mathrm{~Hz}$ center frequency in Figure 5 was consistent with the rank order found with the overall A-weighted levels in Figure 4. However, at the low- $(400 \mathrm{~Hz})$ and high-frequency band $(5000 \mathrm{~Hz})$, the rank order indicated in spectra analysis is not consistent with the overall A-weighted levels' rank order.

7.2. Comparison of the Noise Performance of DGA Pavements in Qatar and Similar Pavements in the US/Europe. A detailed literature review was conducted regarding the noise level of DGA pavements as there is no record of tire-pavement noise in the Gulf region. OBSI test results of DGA pavements in
Qatar were compared to the similar noise data obtained for DGA pavements in the US and Europe. However, difficultly arises when comparing noise data measured at different countries because of variation of test techniques, use of different vehicles in testing, test tires, driver's influence, and meteorological condition during testing [4]. For example, most tire-pavement noise measurements were conducted in Europe by using the close proximity trailer method. Furthermore, most of the noise testing in Europe was conducted using the Goodyear Aquatred 3 tire, which generally produces higher noises than the standard reference test tire manufactured by Uniroyal Tiger Paw [4]. Therefore, only OBSI testing conducted by the standard reference test tire in Europe and the US is considered for comparison purposes. Table 4 presents the available pavement data for DGA pavements in Europe and the US. Figure 6 shows the ranking of the OBSI level for DGA pavements in Qatar, the US, and Europe. The measured intensity level of tested pavements in Qatar is from $100.9 \mathrm{~dB}$ (A) to $101.7 \mathrm{~dB}$ (A) for freshly paved sections, $100.7 \mathrm{~dB}(\mathrm{~A})$ and $104.1 \mathrm{~dB}(\mathrm{~A})$ for pavements aged between one and seven years, and between $105.0 \mathrm{~dB}(\mathrm{~A})$ and $107.1 \mathrm{~dB}(\mathrm{~A})$ for pavement sections having aged over nine years. The ranges of the noise level for DGA surfaces observed for pavement surfaces in Qatar are slightly higher in comparison to the noise level observed for the DGA surface in the US and Europe, where the average noise level on DGA pavements is about $98-102 \mathrm{~dB}$ (A) for freshly laid pavement 


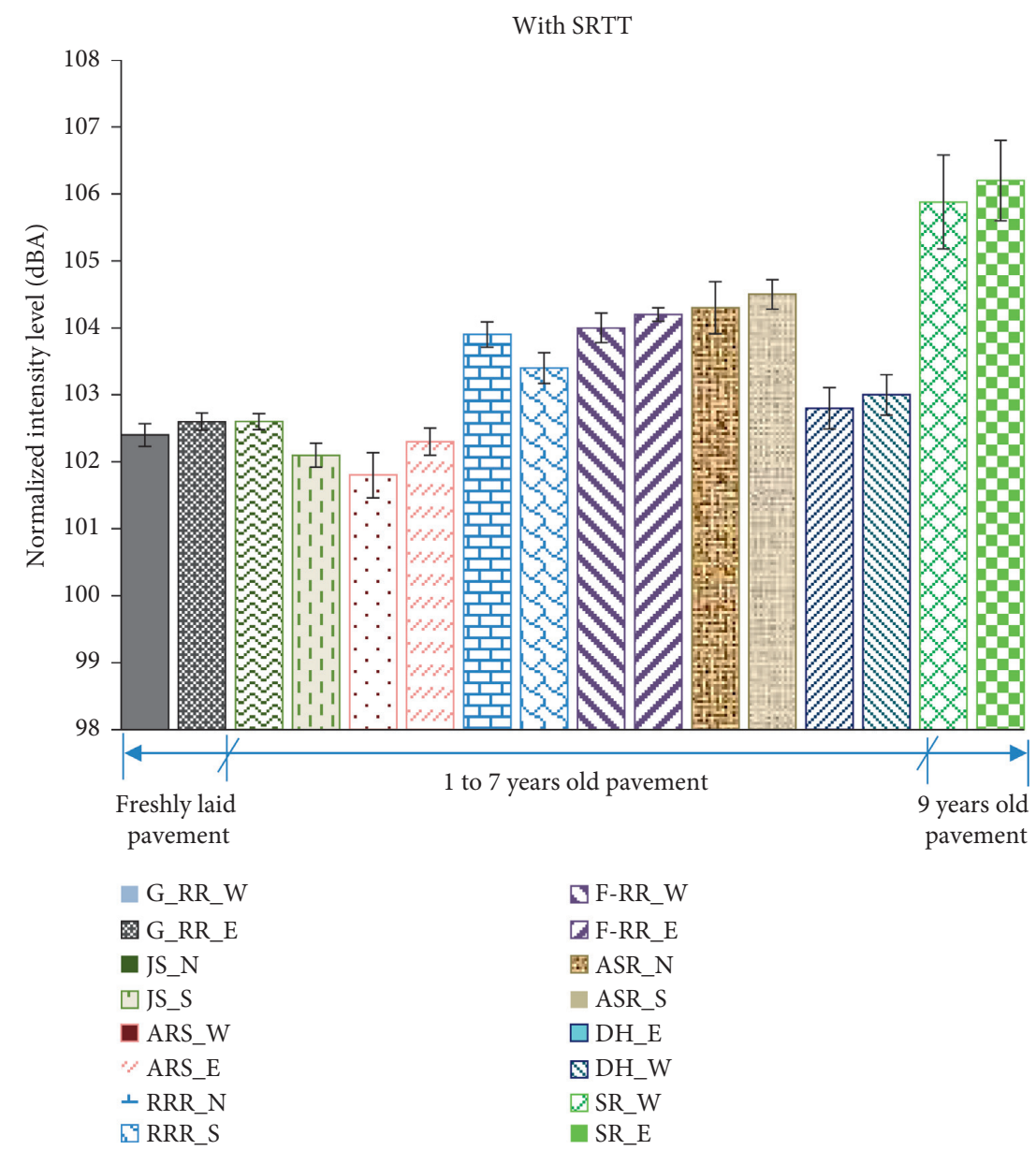

FIGURE 4: Normalized sound intensity level for DGA pavement surfaces in Qatar.

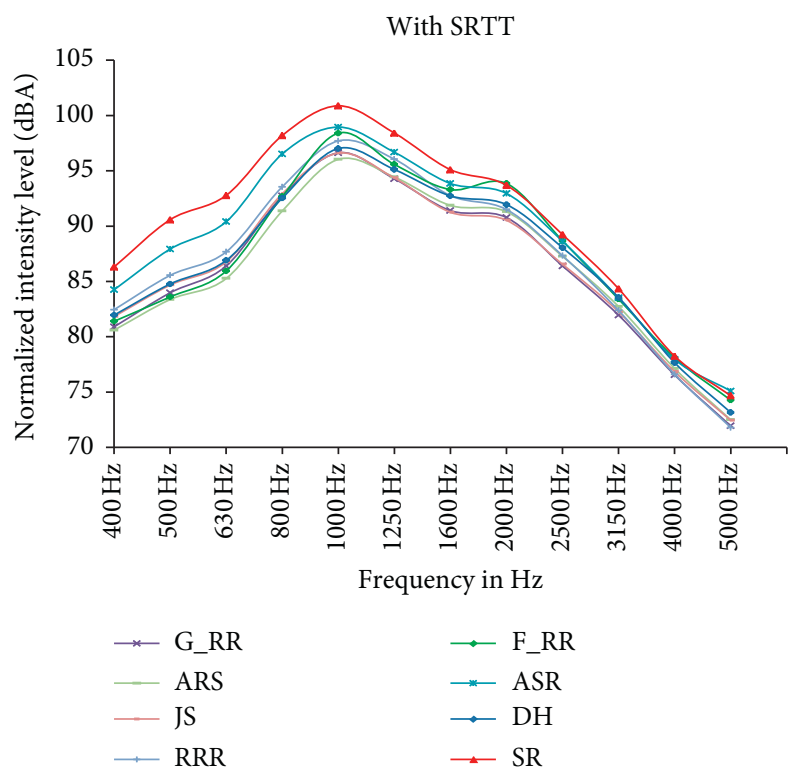

Figure 5: Frequency responses for DGA pavement surfaces.

surfaces, and between 102 and $106 \mathrm{~dB}$ (A) for aged pavements, as presented in Figure 6 [4, 18-20, 22-25]. This is probably because asphalt pavements in Qatar were constructed using dense-graded mixtures with a nominal maximum aggregate size of $14 \mathrm{~mm}, 19 \mathrm{~mm}, 25 \mathrm{~mm}$, and $28 \mathrm{~mm}$ [9]. In terms of tire-pavement noise, it is expected 
TABLE 4: Available pavement data for dense-graded asphalt pavement surfaces in the US and Europe.

\begin{tabular}{|c|c|c|c|c|}
\hline Reference & State/Country & Age of pavement (years) & NMAS $(\mathrm{mm})$ & Pavement ID \\
\hline \multirow{4}{*}{ Donavon [4] } & California/US & New & 12.5 & CA/US-1 \\
\hline & France & - & 10 & France \\
\hline & Germany & - & 8 & Germany \\
\hline & Netherland & - & - & Netherland \\
\hline Wang et al. [18] & North Carolina/US & - & 9.5 & $\mathrm{NC} / \mathrm{US}$ \\
\hline \multirow{2}{*}{ Edwin [19] } & \multirow{2}{*}{ MA/US } & 2 & 9.5 & MA/US-1 \\
\hline & & - & 19 & MA/US-2 \\
\hline \multirow{4}{*}{ Ongel et al. [20] } & \multirow{4}{*}{ California/US } & 3 & 12.5 & CA/US-2 \\
\hline & & 4 & 12.5 & CA/US-3 \\
\hline & & 1 & 19 & CA/US-4 \\
\hline & & 2 & 19 & CA/US-5 \\
\hline \multirow{2}{*}{ UWA and WASDOT [21] } & \multirow{2}{*}{ WA/US } & 1.5 & 12.5 & WA/US-1 \\
\hline & & 2.5 & 12.5 & WA/US-2 \\
\hline
\end{tabular}

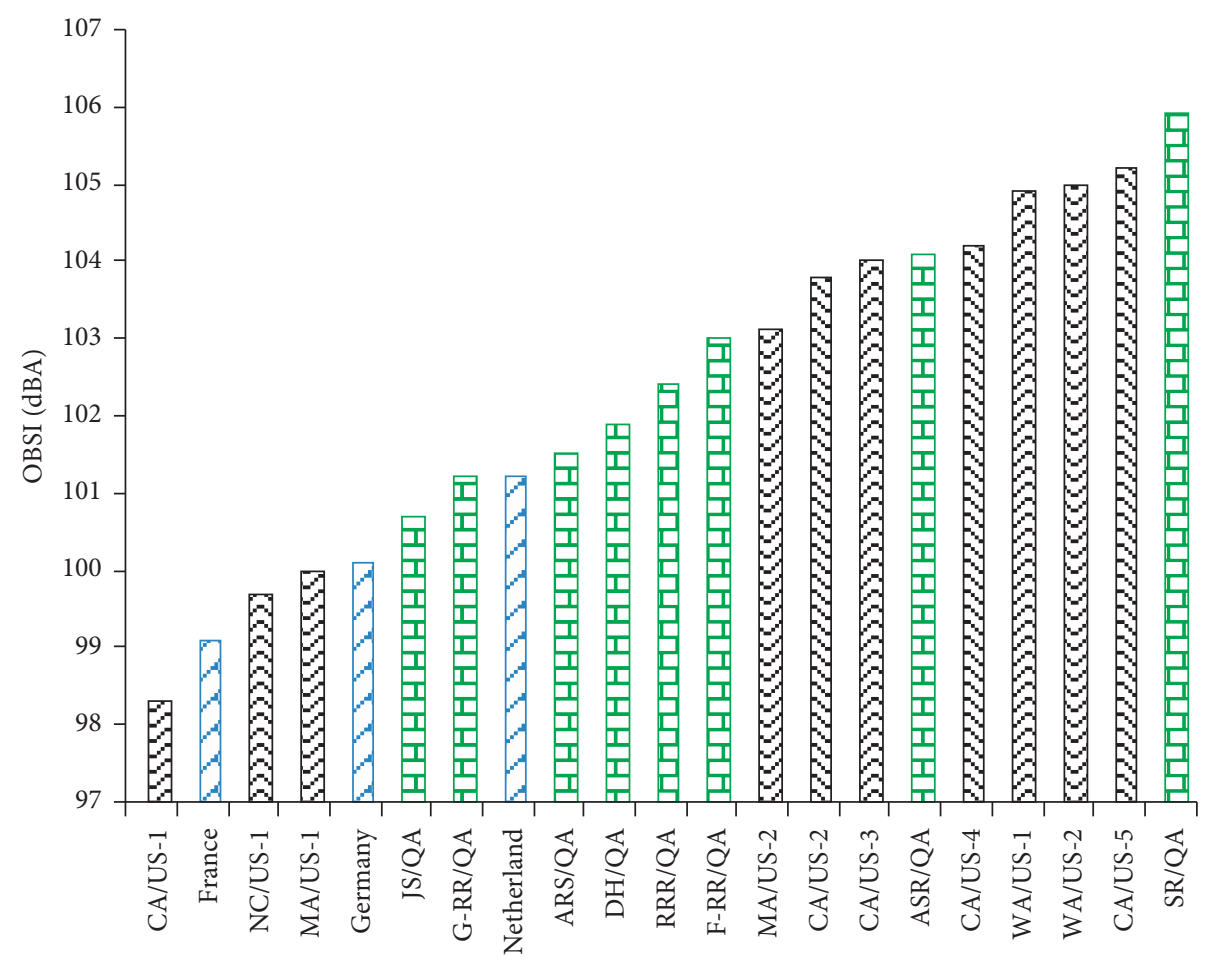

\section{DGA/US \\ D. DGA/europe \\ ए DGA/qatar}

FIGURE 6: Comparison of measured noise intensity levels for DGA pavements in Qatar, Europe, and the US.

that dense-graded mixtures with a larger nominal maximum aggregate size would provide a high level of noise $[4,8]$. The common aggregates used in the construction of the surface course of pavements in Qatar are gabbro as it can resist weathering and abrasive actions. The Micro-Deval abrasion test showed only $27 \%$ loss of angularity for gabbro aggregates [9]. It is expected that pavements constructed using aggregates with high angularity and texture would produce a high noise level.

Noise testing was conducted at relatively low temperatures in Europe (15 C-21 C) and the US (13 C-32 C) in comparison to testing temperature in Qatar, where most of the noise tests were conducted at a higher temperature (greater than $35 \mathrm{C}$ ). Therefore, the normalized OBSI level (normalization conducted at $20 \mathrm{C}$ according to AASHTO $\mathrm{T}$ 360-16) for pavements in Qatar is also compared with similar pavement types in the US and Europe. It can be seen from Figure 7 that the normalized OBSI level for Qatar pavements was much higher than those of pavements in the US and Europe. This demonstrated the influence of air temperature on acoustic performance during testing. 

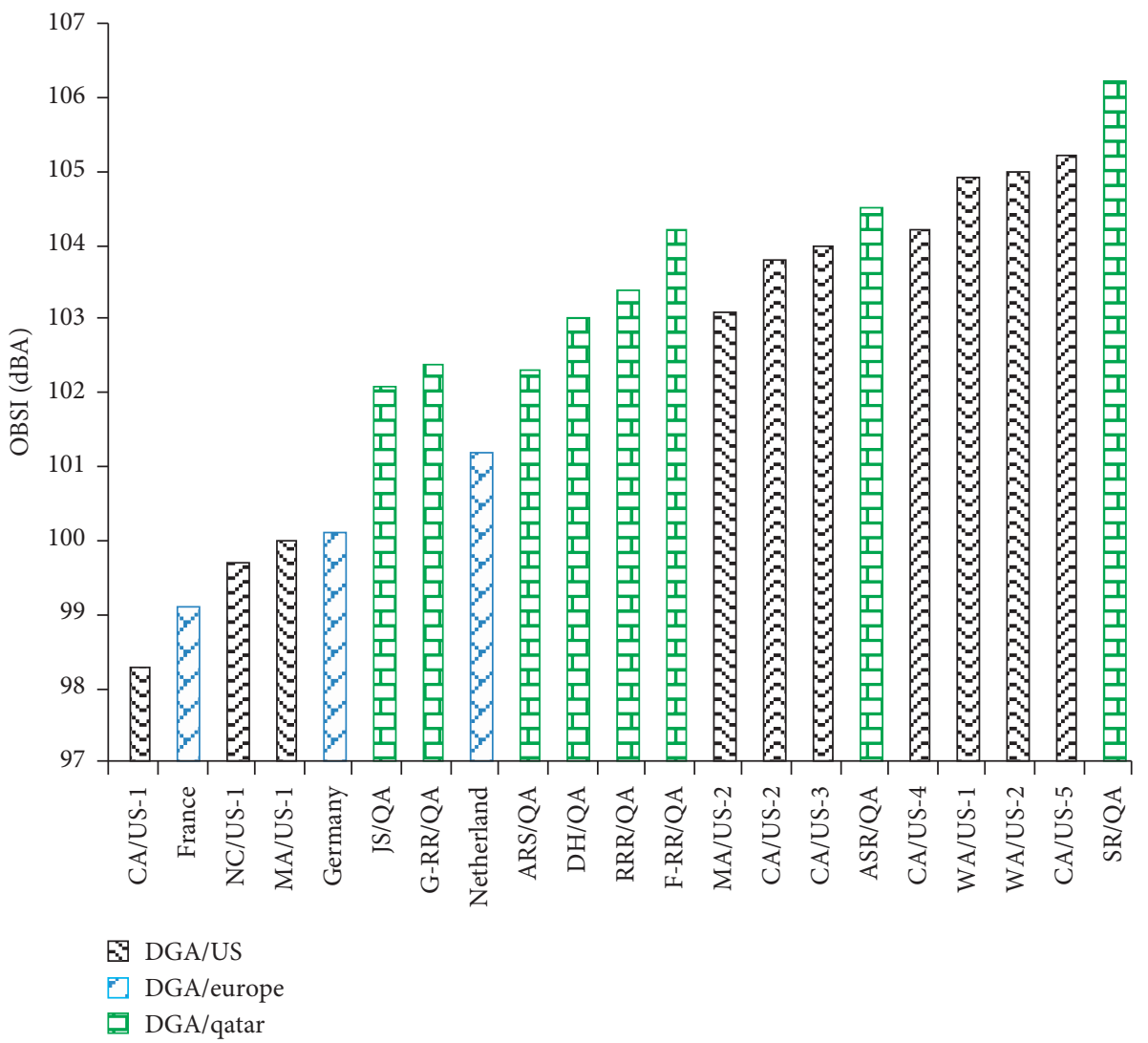

FIGURE 7: Comparison of normalized noise intensity levels for DGA pavements in Qatar, Europe, and the US.

7.3. Correlation between OBSI and Pavement Surface Texture. Macrotexture of the pavement surface is one of the primary factors that affect tire-pavement noise. The volume of air cavities changes with macrotexture, affecting noise generation mechanisms such as air pumping and resonance mechanisms [26]. However, the relationship between surface macrotexture and tire-pavement noise is not well established since surface macrotexture is also influenced by the asphalt mixture's porosity and stiffness [20,27]. Also, the overall macrotexture level cannot be used to relate tirepavement noise with different pavement types. Nevertheless, the relationship between macrotexture of pavement and tirepavement noise has been developed within selected pavement types $[8,20]$. Macrotexture is generally measured using three techniques: laser profilometer, circular texture meter, and sand patch method. Of all the available measurement methods, the sand patch test is the most often used and less expensive test method. In addition, other test methods for measuring macrotexture are often referenced to the sand patch test [26]. Therefore, the sand patch test method was selected for pavement surface macrotexture measurement in this study. In this method, a known volume of sand is spread over the pavement surface, and the area of spread materials is measured [28]. Then, the mean texture depth (MTD) is calculated by the ratio of volume and the area of spread materials. These tests were performed in compliance with ASTM E965 [28]. The relation between OBSI value and MTD of different pavement sections was investigated and presented in Figure 8. It can be observed that there is a correlation between measured overall OBSI and MTD, and the correlation coefficient is $R^{2}=0.7235$. It is indicated that there exists a certain correlation between the pavement macrotexture and OBSI value of the dense-graded asphalt pavement.

To further investigate the relationship between macrotexture and noise level of the pavement, the noise date is analyzed at the $1 / 3^{\text {rd }}$ band frequency level and presented in Figure 9. Linear regression analysis of test data showed a good correlation (Figure 9) between MTD of the pavement surface and OBSI level for frequencies below $1600 \mathrm{~Hz}(500$, 1000 , and $1250 \mathrm{~Hz}$ ). In general, at lower frequency (below $1600 \mathrm{~Hz}$ ), the noise level increases with the increase of MTD of the dense-graded asphalt surface and is in line with the previous studies $[12,20,29,30]$. This is because in frequency below $1250 \mathrm{~Hz}$, the tire vibration mechanism due to thread impacts is primarily responsible for tire-pavement noise [12]. With the increasing of the MTD pavement surface, the thread impact of the tire increases due to induced radial and some tangential vibrations of tire thread and belts, which is expected to produce higher noise [12]. However, it can be seen from Figure 9 that there is no or limited correlation existing between pavement MTD and OBSI level at the higher frequency $1 / 3^{\text {rd }}$ octave band (frequency above $2000 \mathrm{~Hz}$ ). This is due to the fact that the air pumping mechanism dominates the noise generation at a higher frequency (frequency above $2000 \mathrm{~Hz}$ ), which is related to air 


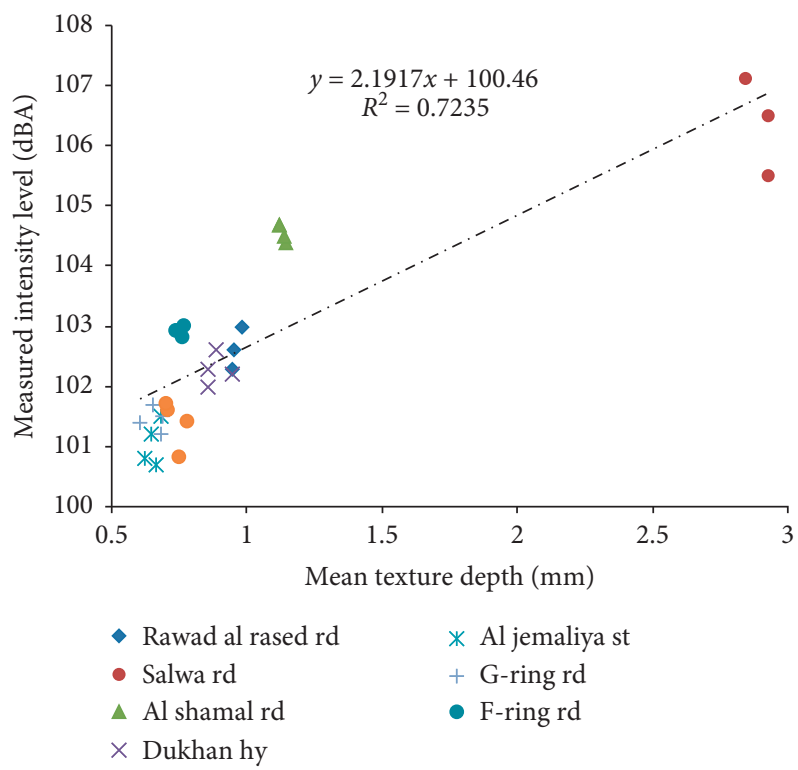

FIGURE 8: Correlation between mean texture depth (MTD) and overall OBSI level for DGA pavement sections.

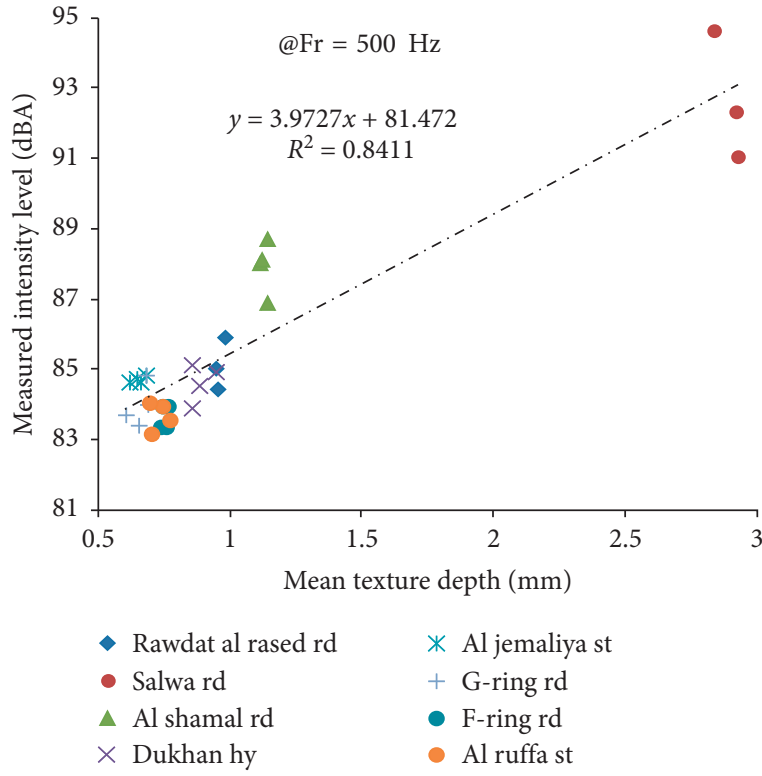

(a)

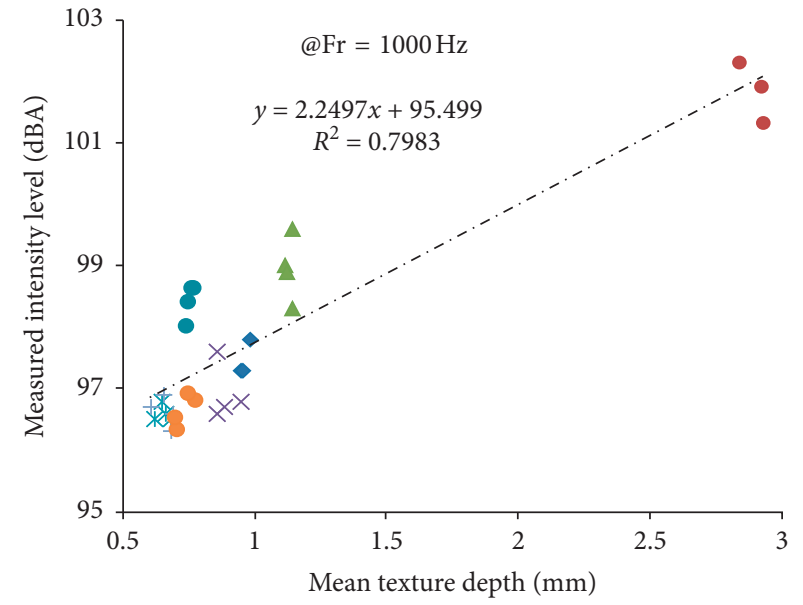
- Rawdat al rased rd
* Al jemaliya st
- Salwa rd
+ G-ring rd
- Al shamal rd
- F-ring rd
$\times$ Dukhan hy
- Al ruffa st

Figure 9: Continued.

(b) 


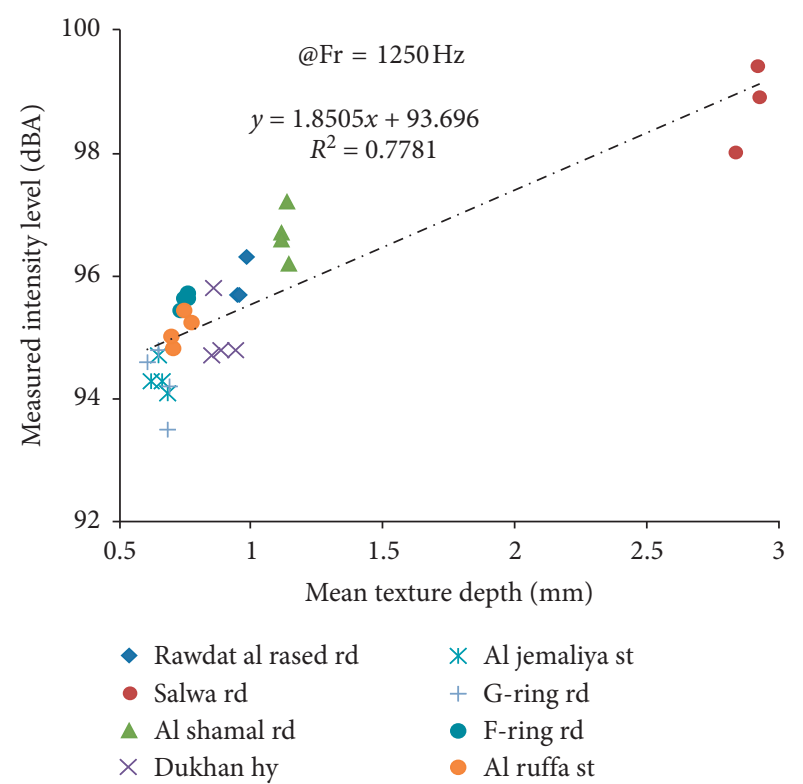

(c)

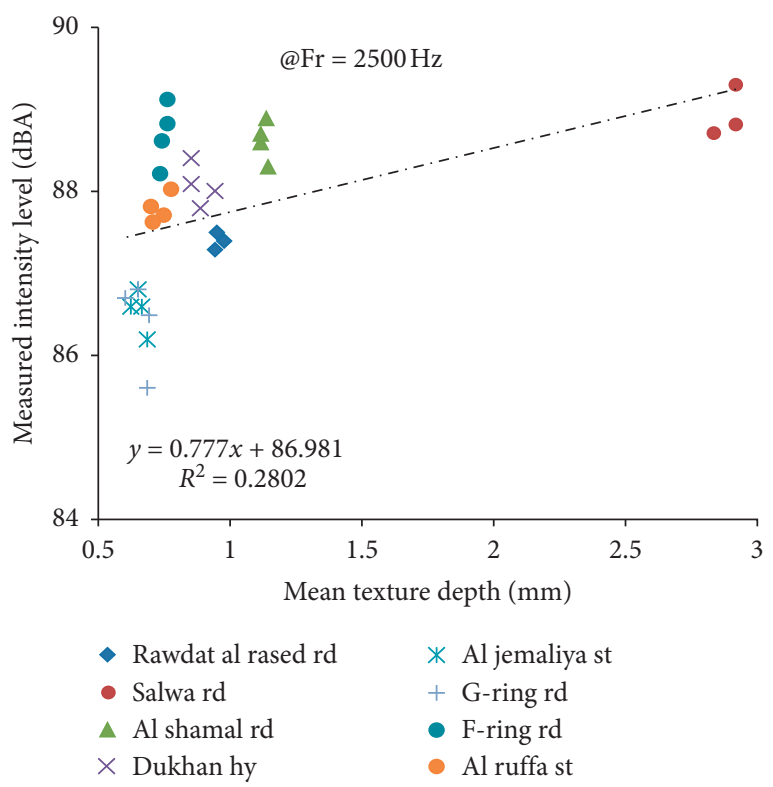

(e)

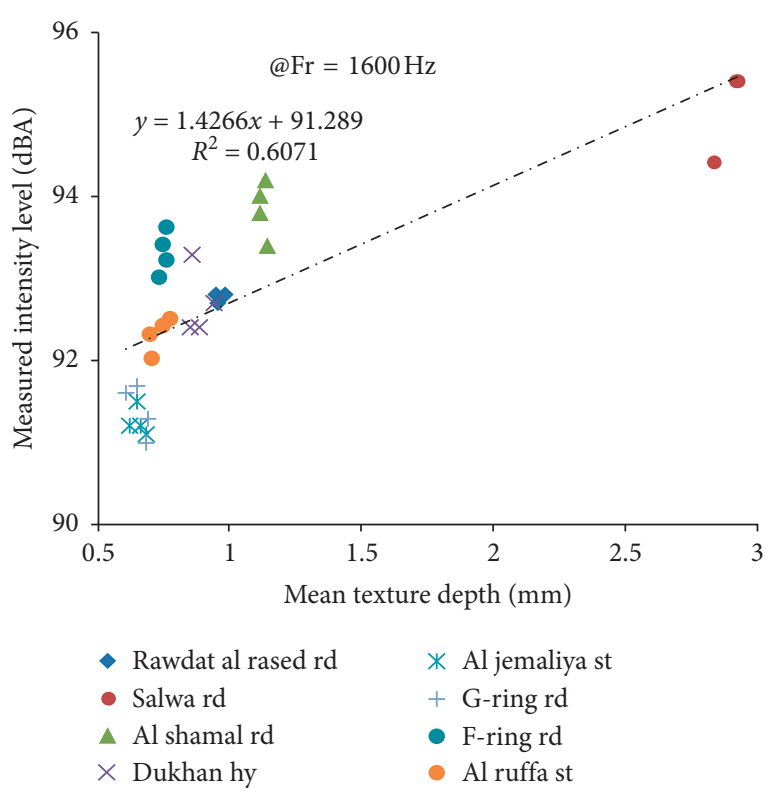

(d)

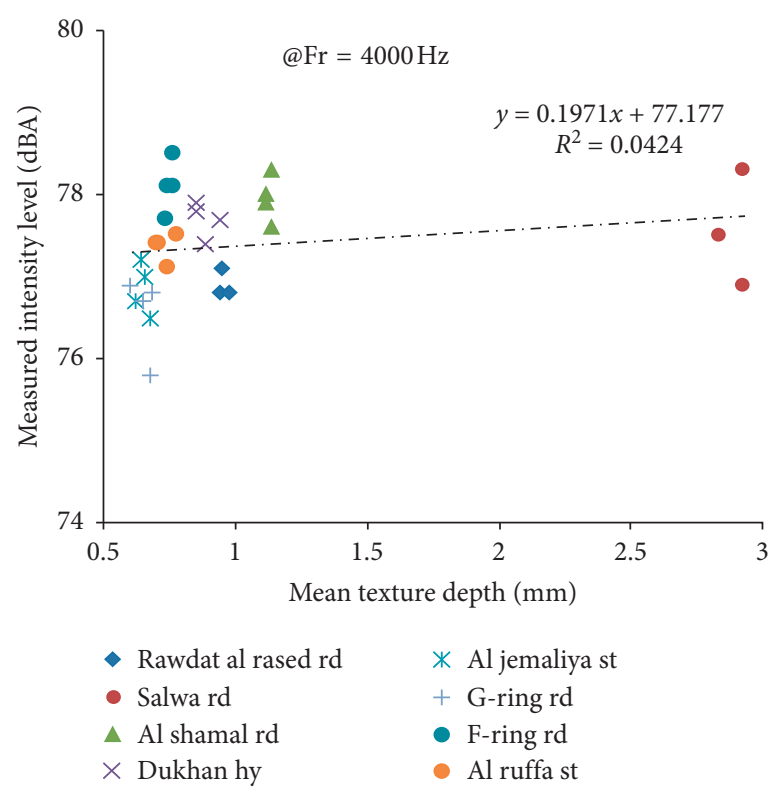

(f)

Figure 9: Correlation between mean texture depth (MTD) and OBSI level at the 1/3rd frequency band.

voids of the mixture; hence, it has a less significant effect for the dense-graded asphalt pavement [12].

7.4. Effect of Tire Type/Size on the Sound Intensity Level. Tread pattern and size of the tire affect the generation of tire pavement noise [12, 31]. Therefore, a controlled experiment with three different tires was conducted to determine the discrete difference between noise levels for different tires. In addition to the standard reference test tire, Oniza tire (P225/ 60R16) and Bridgestone tire (P215/60R16), commonly used in Qatar, were used to examine the influence of tire thread type/dimension on the generation of tire-pavement noise. The photographic view of three types of tires is shown in Figure 10. The hardness of each tire was measured following the ASTM D-2240-05 [11] specification before and after using the tires to observe any difference in the hardness level. OBSI tests were performed on nine sections of Rawad Al Rashed Road, an arterial road connecting two major highways (i.e., Salwa Road and Dukhan Highway). These pavement sections were constructed in 2016, and the surface layer was constructed with NMAS of $19 \mathrm{~mm}$. The environmental conditions varied slightly from one type of tire to another; hence, all the test results were normalized 


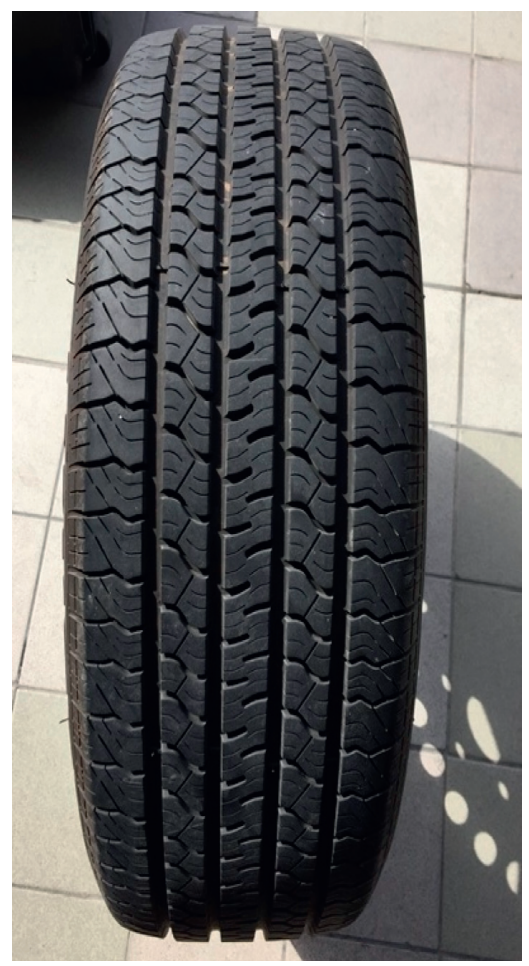

(a)

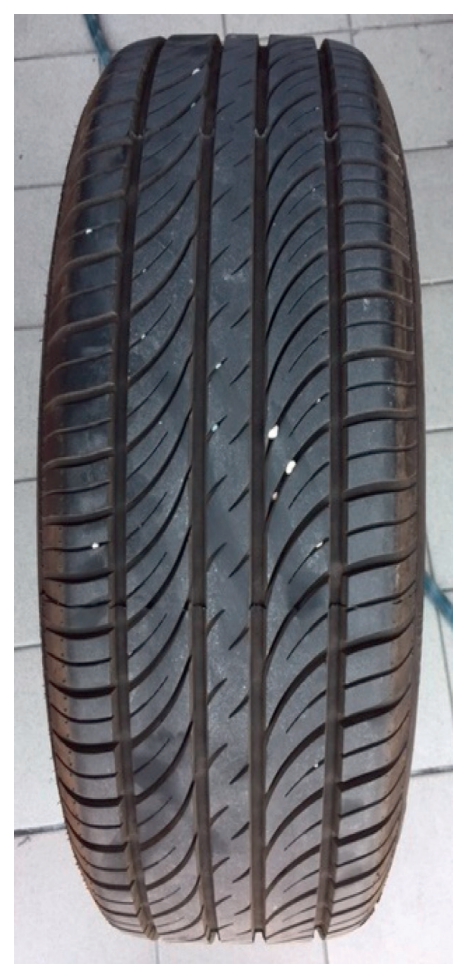

(b)

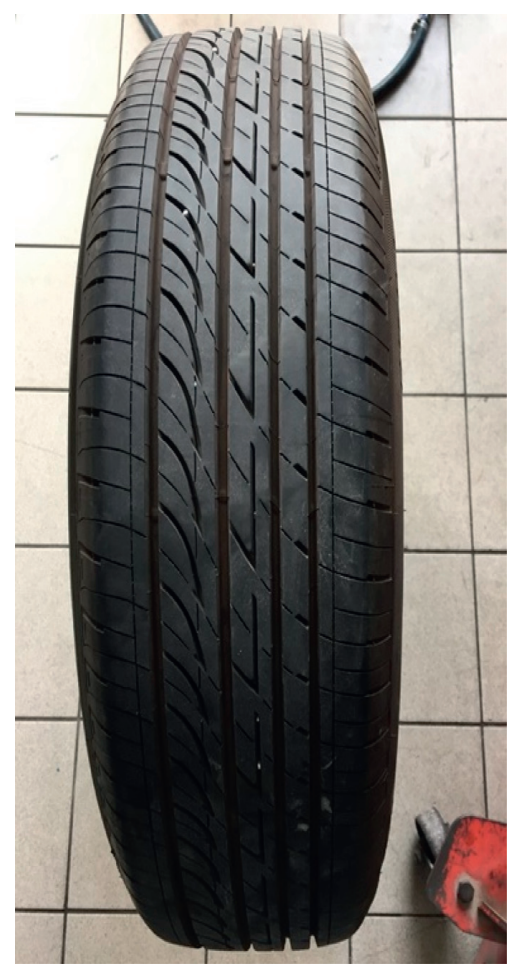

(c)

Figure 10: Types of tires used in the study. (a) Standard reference test tire. (b) Oniza. (c) Bridgestone.

according to AASHTO T 360-16 [7] normalization procedure to avoid any bias due to any changes in the climatic conditions.
Figure 11 shows the overall OBSI levels for all three types of tires for each pavement section. The overall OBSI levels varied significantly among the tires, and generally, the tires 


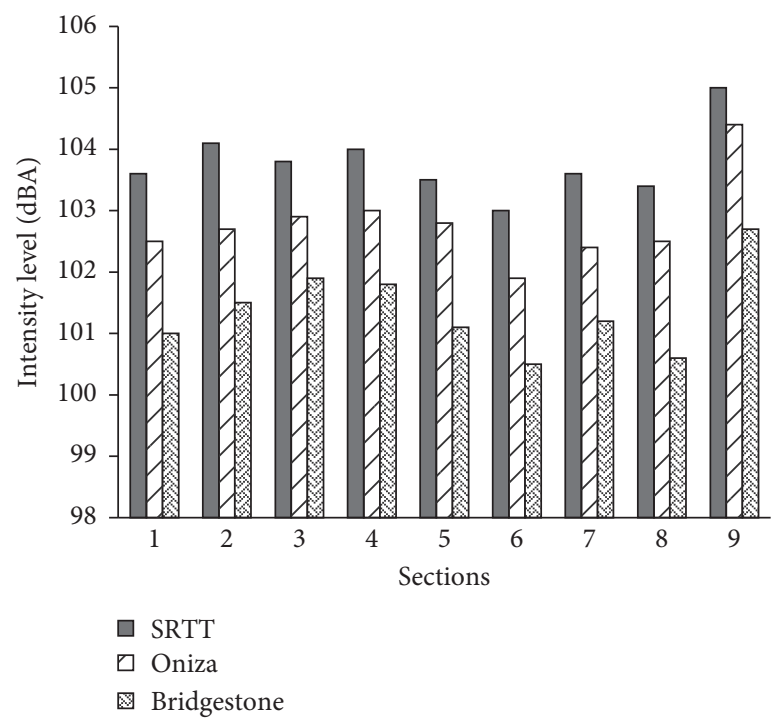

FIGURE 11: Effects of tire type/size on the OBSI level.

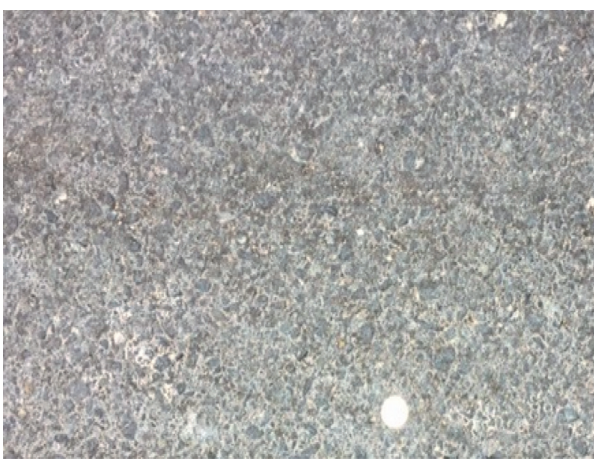

(a)

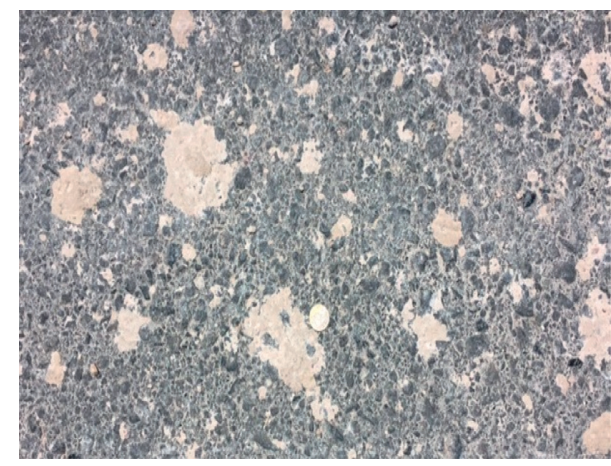

(b)

Figure 12: A photographic view of Rawad Al Rashed road. (a) Typical section. (b) Section with dirt.

consistently exhibited results in the order from loudest to quietest, with the standard reference test tire being the loudest, followed by Oniza and Bridgestone, respectively. The overall sound intensity level difference between the standard reference test tire and Bridgestone tire is almost $2.4 \mathrm{dBA}$, which is reasonable as the size of the latter tire is smaller compared to the standard reference test tire.

The difference among the overall OBSI level for Sections $1-8$ is very small $(0.5 \mathrm{dBA})$ for all three types of tires. However, the difference is much higher (over $2 \mathrm{dBA}$ ) than Section 9 and the rest of the other sections. The presence of dust on the pavement Section 9 contributed to higher noise, as shown in Figure 12. The accumulation of dust was due to the entering of construction trucks to the pavement facility with mud and soil stuck to their tires. This is currently a common feature in Qatar roads as infrastructure construction is almost everywhere to meet its 2030 vision deadlines.

Figure 13 shows the frequency response of various tires for a pavement test section. It can be observed from Figure 13 that the standard reference test tire appeared to have a significant peak at the $1000 \mathrm{~Hz}$ center frequency compared to the other two types of tires. The higher peak for the standard reference is the dominating factor in justifying the higher overall OBSI level for the standard reference test tire. It is also apparent from Figure 13 that, at a frequency higher than $2500 \mathrm{~Hz}$, the Bridgestone tire has a higher value of sound intensity compared to other types of tires. This indicates that the air pumping mechanism is higher for the Bridgestone tire compared to the two other tires.

7.5. Effect of Vehicle Speed on the Sound Intensity Level. Past research studies demonstrated the increase of sound noise with increasing vehicle speed irrespective of the tire and pavement type $[12,19,32-35]$. Therefore, the OBSI tests were performed on three varying aged pavement surfaces to investigate the effect of vehicle speed on sound intensity levels. The sound intensity level variation with the vehicle speed for three selected pavement sections can be seen in Figure 14. The relatively high $R^{2}$ value of 0.99 of the trendline equation is also observed in previous studies $[18,33]$, demonstrating a strong 


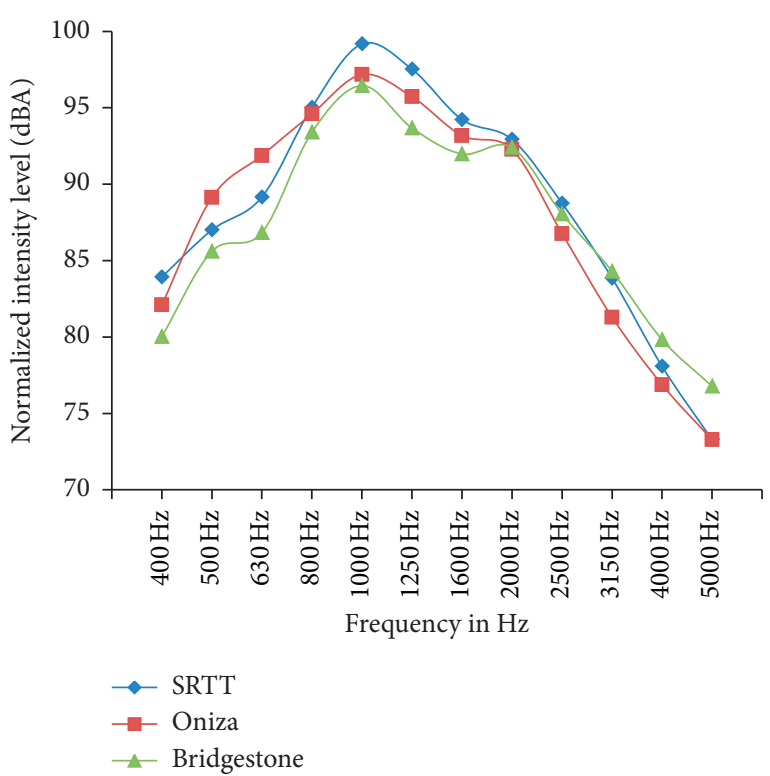

Figure 13: Frequency response of tested tires for Section 1.

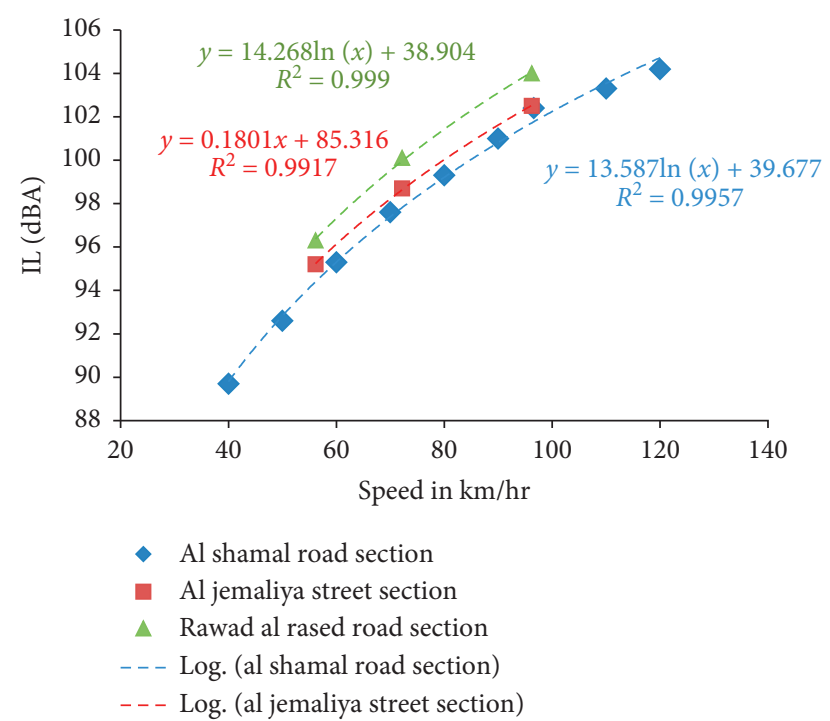

FIGURE 14: Variation of the intensity level with driving speed for SRTT.

correlation between OBSI value and vehicle speed. The average slope of all three measurements reflects an increase in the overall intensity level with increasing vehicle speed. The effect of speed for different tires is also evaluated, and the test results are shown in Figure 15. From the logarithmic relationship, it is also demonstrated that the OBSI level decreased with reducing vehicle speed. This may be an important factor for Qatar's transport authorities considering reducing traffic noise in populated urban areas.

\section{Summary of Findings and Conclusions}

The acoustic performances of eight dense-graded asphalt pavements, including 130 sections representing the most common pavement types constructed in the State of Qatar,

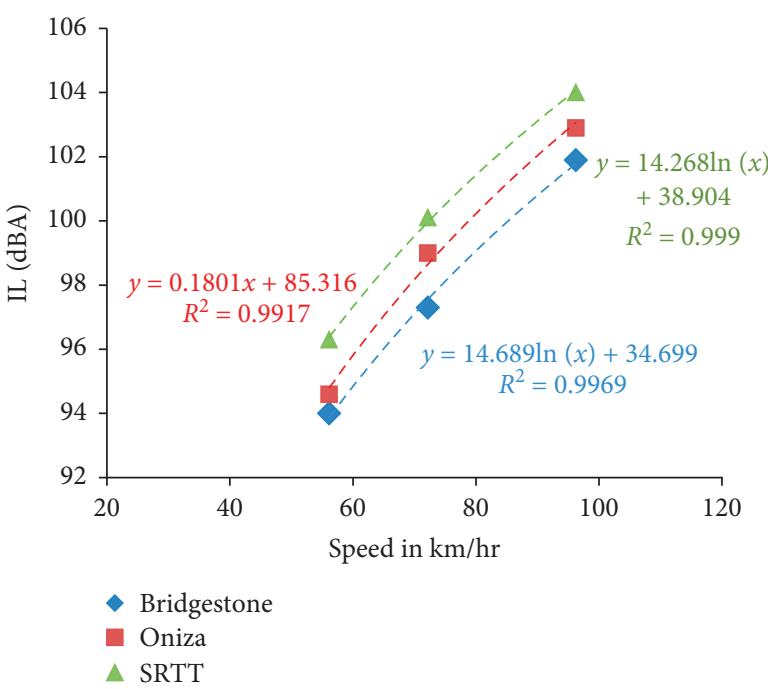

FIGURE 15: Variation of the intensity level with driving speed for different types of tire.

were examined in this study. The researchers assembled a testing setup to measure tire-pavement noise at the source using the OBSI system in accordance with the AASHTO T 360-16 standard. Test results demonstrated that the established noise testing setup can measure the sound intensity with excellent repeatability and reproducibility. The acoustics' performance of pavements in Qatar was then compared with similar dense-graded asphalt pavements in the US and Europe. Based on the OBSI testing conducted on various pavement sections in Qatar, the main findings can be summarized as follows:

Pavements in Qatar generated higher noise compared to the similar type of pavements in Europe and the US. The surface layer of pavements in Qatar is generally constructed with larger nominal maximum aggregate sizes $(20 \mathrm{~mm}, 19 \mathrm{~mm}$, and $14 \mathrm{~mm})$, which contributed to generating higher noise levels.

The measured noise level of existing pavements varied from 101.8 dBA to 106.2 dBA depending on the age of pavement sections. This demonstrated that the noise level increases with the increasing age of the pavement surface. However, the acoustic performance of pavements in Qatar deteriorates faster with aging compared to the noise performance of pavements in the US and Europe. Qatar's pavements are exposed to harsh climatic conditions during summer (temperature often reaches or exceeds $40 \underline{\mathrm{o} C}$ ), contributing to various distresses, especially fatigue cracking under heavy traffic. These distresses may lead to higher noise levels. Pavements prepared with aggregates with larger nominal maximum aggregate size produced higher noise compared to those with smaller nominal aggregate size.

Macrotexture of the pavement, represented in terms of mean texture depth, was an important factor affecting tire-pavement noise. The higher mean texture of depth 
pavement surfaces generally corresponds to higher noise levels, especially at a lower frequency (less than $1600 \mathrm{~Hz}$ ).

The tire-pavement noise was significantly affected by the vehicle speed and generally increased with the increase in speed. This trend was independent of pavement and tire types. This could be an important consideration for reducing traffic noise in major cities such as Doha.

The OBSI level was found to be affected by the tire thread type and size of the tire. The standard reference test tire provided higher OBSI levels compared to the other two locally available tires (Oniza and Bridgestone) evaluated in this study.

As there is no record of OBSI measurements conducted in the Arabian Gulf to the best of the authors' knowledge, thus these test results would be of interest to the regional transportation agencies. The authors recommend constructing test sections of alternative pavement types (e.g., porous friction course and stone matrix asphalt) to evaluate their acoustic performance and assess possible advantages over the conventional dense-graded asphalt pavements currently used in Qatar.

\section{Data Availability}

The data used to support the findings of this study are included within this article.

\section{Conflicts of Interest}

The authors declare that they have no conflicts of interest.

\section{Acknowledgments}

This study was supported by the NPRP grant (NPRP 7-110-2-056) from the Qatar National Research Fund (a member of Qatar Foundation). The findings herein reflect the work, and are solely the responsibility, of the authors.

\section{References}

[1] U. Sandberg, "Tire/road noise-Myths and realities," in Proceedings of the 2001 International Congress and Exhibition on Noise Control Engineering the Hague, The Netherlands, August 2001.

[2] R. Rasmussen and C. Sohaney, Tire-pavement and Environmental Traffic Noise Research Study, The Transtec Group, Inc., Austin, TX, USA, 2012.

[3] M. Ohiduzzaman, O. Sirin, E. Kassem, and J. Rochat, "Stateof-the-art review on sustainable design and construction of quieter pavements-part 1: traffic noise measurement and abatement techniques," Sustainability, vol. 8, no. 8, p. 742 , 2016.

[4] P. Donavan, Comparative Measurements of Tire-Pavement Noise in Europe and the United States, Report Number: FHWA/CA/MI-2006/09, California Department of Transportation, Sacramento, CA, USA, 2006.
[5] L. Scofield and P. Donavan, Development of Arizona's Quiet Pavement Research Program, Arizona Department of Transportation, Arizona, 2006.

[6] L. Oswald and P. Donavan, Acoustic Intensity Measurements in Low Mach Number Flows of Moderate Turbulence Levels, Research Publication GMR-3269 General Motors Research Laboratories, Warren, MI, USA, 1980.

[7] AASHTO, AASHTO T 360-16-Standard Method of Test for Measurement of Tire-Pavement Noise Using the On-Board Sound Intensity (OBSI) Method, American Association of State and Highway Transportation Officials, Washington, DC, USA, 2016.

[8] K. Kowalski, "Influence of mixture composition on the noise and frictional characteristics of flexible pavements," Ph.D. Thesis, Purdue University, West Lafayette, IN, USA, 2007.

[9] E. Masad, E. Kassem, and D. Little, "Characterization of asphalt pavement materials in the state of Qatar," Road Materials and Pavement Design, vol. 12, no. 4, pp. 739-765, 2011.

[10] ASTM, ASTM F2493-08-Standard Specification for P225/ 65R16 97S Radial Standard Reference Test Tire, ASTM International, West Conshohocken, PA, USA, 2008.

[11] ASTM, ASTM D2240-05 Standard Test Method for Rubber Property-Durometer Hardness, ASTM International, West Conshohocken, PA, USA, 2010.

[12] U. Sandberg and A. Ejsmont, Tire/road Noise Reference Book, Informex, Kisa, Sweden, 2002.

[13] O. Sirin, M. Ohiduzzaman, and E. Kassem, "Evaluation of noise performance of multi-lane highways in the State of Qatar," IOP Conference Series, Materials Science and Engineering, vol. 517, 2019.

[14] P. Donavan and D. Lodico, "Measuring tire-pavement noise at the source: precision and bias statement," National Cooperative Highway Research Program NCHRP Project: 1-44, Transportation Research Board: Washington D.C, Washington DC, USA, 2011.

[15] G. Licitra, A. Moro, L. Teti, A. Del Pizzo, and F. Bianco, "Modelling of acoustic ageing of rubberized pavements," Applied Acoustics, vol. 146, pp. 237-245, 2019.

[16] O. Sirin, M. Ohiduzzaman, and E. Kassem, "Effect of pavement surface aging on tire-pavement noise: a case study in the State of Qatar," MATEC Web of Conferences, vol. 203, 2018.

[17] A. Rezaei, J. Harvey, and R. Wu, "Investigation of noise and durability performance trends for asphaltic pavement surface types: five-year results," Research Report: UCPRC-RR-2012, California Department of Transportation Division of Research and Innovation Office of Roadway Research, CA, USA, 2011.

[18] G. Wang, G. Smith, and R. Shores, "Pavement noise investigation on North Carolina highways: an on-board sound intensity approach," Canadian Journal of Civil Engineering, vol. 39, no. 8, pp. 878-886, 2012.

[19] H. Edwin, "Evaluating tire-pavement noise utilizing the onboard sound intensity method," Master's Thesis, Graduate School-New Brunswick, Rutgers, NJ, USA, 2013.

[20] A. Ongel, J. Harvey, E. Kohler, Q. Lu, and B. Steven, "Investigation of noise, durability, permeability, and friction performance trends for asphaltic pavement surface types: first- and second-year results," Research Report-UCDITS-RR-08-49, University of California, Pavement Research Center, UC Davis, UC Berkeley, 2008.

[21] UWA and WASDOT, "Quieter pavement performance in Washington State," in Proceedings of the PowerPoint 
Presentation, Rocky Mountain Asphalt Conference, Denver, CO, USA, January 2009.

[22] R. Kleiziene, O. Sernas, A. Vaitkus, and R. Simanaviciene, "Asphalt pavement acoustic performance model," Sustainability, vol. 11, no. 10, p. 2938, 2019.

[23] X. Lu, J. Kang, P. Zhu, J. Cai, F. Guo, and Y. Zhang, "Influence of urban road characteristics on traffic noise," Transportation Research Part D: Transport and Environment, vol. 75, pp. 136-155, 2019.

[24] R. Rasmussen, R. Bernhard, U. Sandberg, and E. Mun, The Little Book of Quieter Pavements. Report FHWA-IF-08-004, FHWA, U.S. Department of Transportation, 2007.

[25] R. Sohaney, R. Rasmussen, P. Donavan, and J. Rochat, Quieter Pavements Guidance Document, Natural Resource Technical Report NPS/NSNS/NRTR—2013/760, National Park Service, Fort Collins, CO, USA, 2013.

[26] S. China and D. E. James, "Comparison of laser-based and sand patch measurements of pavement surface macrotexture," Journal of Transportation Engineering, vol. 138, no. 2, pp. 176-181, 2012.

[27] M. Staiano, "Tire-pavement noise and pavement texture," Journal of Transportation Engineering, Part B: Pavements, vol. 144, no. 3, 2018.

[28] ASTM, ASTM E965-15 Standard Test Method for Measuring Pavement Macrotexture Depth Using a Volumetric Technique, American Society of Testing and Material, West Conshohocken, PA, USA, 2015.

[29] G. Liao, M. S. Sakhaeifar, M. Heitzman et al., "The Effects of pavement surface characteristics on tire/pavement noise," Applied Acoustics, vol. 76, pp. 14-23, 2014.

[30] M. Sakhaeifar, A. Banihashemrad, G. Lioa, and B. Waller, "Tyre-pavement interaction noise levels related to pavement surface characteristics," Road Materials and Pavement Design, vol. 19, no. 5, 2018.

[31] G. Licitra, L. Teti, M. Cerchiai, and F. Bianco, "The influence of tyres on the use of the CPX method for evaluating the effectiveness of a noise mitigation action based on low-noise road surfaces," Transportation Research Part D: Transport and Environment, vol. 55, pp. 217-226, 2017.

[32] A. Can and P. Aumond, "Estimation of road traffic noise emissions: the influence of speed and acceleration," Transportation Research Part D: Transport and Environment, vol. 58, pp. 155-171, 2018.

[33] P. Donavan and D. Lodico, "Measuring tire-pavement noise at the source," NCHRP Report 630, National Cooperative Highway Research Program, Transportation Research Board of the National Academies, Washington DC, USA, 2009.

[34] T. Li, "A state-of-the-art review of measurement techniques on tire-pavement interaction noise," Measurement, vol. 128, pp. 325-351, 2018.

[35] O. Sirin, "State-of-the-art review on sustainable design and construction of quieter pavements-part 2: factors affecting tire-pavement noise and prediction models," Sustainability, vol. 8 , no. 7 , p. $692,2016$. 